\title{
MECANISMO DE SUPERAÇÃO DE PRECEDENTES COMO GARANTIA DA SEGURANÇA JURÍDICA SEM A PERDA DA EVOLUÇÃO DO DIREITO
}

\author{
PRECEDENT SUPPRESSION MECHANISM AS GUARANTEE OF LEGAL SECURITY \\ WITHOUT LOSS OF EVOLUTION OF THE LAW
}

\author{
Judah Henrique Pinheiro de Figueiredo ${ }^{1}$ \\ Lyvio Moizés Vasconcelos Vieira²
}

\section{RESUMO:}

O Novo Código de Processo Civil de 2015 trouxe inúmeras inovações para o direito brasileiro, com o intuito de dirimir problemas que os órgãos judiciais enfrentavam há tempos. Neste trabalho, observou-se quais inovações e soluções obtidas pela teoria dos precedentes. Ademais, trata acerca da crítica a referida doutrina, em que conjectura a possibilidade de haver um engessamento do direito. Com isso, o objetivo geral consiste em demonstrar que a teoria dos precedentes trouxe vantagens ao direito pátrio, além de fomentar a efetivação do princípio da segurança jurídica e equidade. De forma específica, discutir que os precedentes não resultam em uma imutabilidade das decisões judiciais. Constatar que a teoria dos precedentes possui mecanismo para evitar a solidificação e inalterabilidade das sentenças, evoluindo o direito e adequandoo à visão da sociedade, proporcionando a aplicação dos princípios jurídicos. A pesquisa se caracteriza por uma revisão de literatura, com caráter exploratório e descritivo, com procedimento bibliográfico, através do método de abordagem hipotético-dedutivo. Por fim, verificou-se que o Novo Código de Processo Civil busca aplicar mais efetivamente a teoria dos precedentes visando uma maior segurança jurídica, ao mesmo tempo que proporciona mecanismo de superação destes institutos, com o afã de garantirem a evolução do direito.

PALAVRAS-CHAVE: Código de Processo Civil. Teoria dos Precedentes. Engessamento das decisões judiciais.

\footnotetext{
${ }^{1}$ Especialista em Processo Civil pela Faculdade Paraíso do Ceará . Graduado em Bacharelado em Direito pela Faculdade Paraíso do Ceará.. Email: judahhenrique@hotmail.com

${ }^{2}$ Especialista em Direito Penal e Criminologia pela Universidade Regional do Cariri . Graduado em Bacharelado em Direito pela Universidade Regional do Cariri. Docente do curso de Direito na Faculdade Paraíso do Ceará. Email: lyviomoizesvv@hotmail.com
} 


\begin{abstract}
:
The New Code of Civil Procedure of 2015 brought innumerable innovations to Brazilian law, with the purpose of solving problems that judicial organs had faced for a long time. Observed which innovations and solutions obtained by the theory of precedents. In addition, it deals with the critique of said doctrine, in which it conjectures the possibility of making the right immutable. Thus, the general objective is to demonstrate that the theory of precedents has given advantages to the brazilian law, in addition to fostering the realization of the principle of legal certainty and equity. Specifically, to argue that precedents do not result in a solidification of judicial decisions. It notes that the theory of precedents has a mechanism to avoid the solidification and immutability of sentences, evolving the law and adapting it to the view of society, as well as provides the application of legal principles. The research is characterized by a literature review, with an exploratory character, with an exploratory and descriptive character, with a bibliographic procedure, through the hypothetical-deductive approach. Finally, it was found that the New Code of Civil Procedure had a more effective application to the theory of precedents in aiming of greater legal certainty, as well as the mechanism for overcoming of these institutes, in order to guarantee the evolution of law.
\end{abstract}

KEYWORDS: Code of Civil Procedure. Theory of Precedents. Immutability of judicial decisions.

\title{
1 INTRODUÇÃO
}

Com a vigência do Novo Código de Processo Civil em 2015, buscou-se solucionar inúmeros problemas que o direito brasileiro adquiriu durante a aplicação do código Buzaid de 1973. O novo códex de ritos de 2015, bebendo, em alguns pontos, na fonte do direito inglês e norte americano, trouxe várias inovações, novos institutos à serem aplicados, entre eles está a teoria dos precedentes, objeto de estudo deste trabalho, o qual tem como escopo trazer maior segurança jurídica e equidade nas decisões dos magistrados.

Todavia, há críticas a tal doutrina, em que se argumenta que sua aplicação trará um engessamento das decisões judiciais devido as suas previsibilidades, além de outras aplicações no campo dos recursos, o que traria mais prejuízos do que benefícios. Deste modo, observa-se os objetivos deste estudo, sendo o geral, demonstrar que a teoria dos precedentes trouxe vantagens ao direito brasileiro, veio fomentar a efetivação do princípio da segurança jurídica e equidade. Quanto ao objetivo 
específico, busca-se demonstrar que os precedentes não resultarão em uma solidificação das decisões e entendimento judiciais, tendo em vista que em seu bojo há mecanismos que impedem tais efeitos.

O plano metodológico tem por base a problemática do presente trabalho, com isso, a pesquisa se caracteriza por uma revisão de literatura, com procedimento bibliográfico, haja vista que utiliza livros, revistas, teses, pesquisas monográficas para embasar e buscar soluções relacionadas à problemática. Neste sentindo, este trabalho reuniu as publicações acerca do tema proposto nos periódicos de Direito, no campo do Processo Civil e da teoria dos precedentes. Desse modo, destacam-se como fontes principais de nossa pesquisa os periódicos eletrônicos, a saber: Portal de Periódicos da Capes; Bibliotecas Digitais de Teses e Dissertações (BDTD); Repositórios institucionais.

Trata-se de um estudo com o método de abordagem hipotético-dedutivo, que se caracteriza por ser do tipo exploratório e descritivo, haja vista que irá demonstrar a presença de mecanismos de superação de precedentes no Código de Processo Civil de 2015 com o afã de evitar o engessamento do direito e proporcionar uma maior segurança jurídica .

\section{DOS SISTEMAS JURÍDICOS}

Antes de tratar sobre a teoria dos precedentes, mister é compreender acerca dos mais importantes e utilizados sistemas jurídicos, o Common Law e Civil Law, haja vista que o direito brasileiro bebe nas fontes dos dois sistemas, mesmo que possuam inúmeras diferenças.

O modelo Civil Law é o mais aderido pelos países do ocidente, incluindo o Brasil, tendo em vista a grande influência da dominação romana por séculos na Europa, impondo sua cultura e leis, daí então o referido sistema também ser conhecido como Sistema Romano Germânico (CARON, 2014). A principal fonte do direito neste sistema é a Lei, a norma positivada emanada da vontade do povo por meio do poder legislativo, seguida pela jurisprudência, decisões reiteradas pelo poder judiciário, e por fim os costumes. Neste contexto, Nader (2011, p. 143) leciona que "para os países que seguem a tradição romano-germânica, como o Brasil, a principal forma de expressão é 
o Direito escrito, que se manifesta por leis e códigos". Reale (2002, p. 110), quanto a origem e sedimentação do Civil Law, afirma que este:

Caracteriza-se pelo primado do processo legislativo, com atribuição de valor secundário às demais fontes do direito. A tradição latina ou continental (Civil Law) acentuou-se especialmente após a revolução francesa, quando a lei passou a ser considerada a única expressão autêntica da nação, da vontade geral, tal como verificamos na obra de Jean-Jacques Rousseau, Du Contrat Social.

No que tange ao ordenamento jurídico do Common Law, este é mais comumente praticado em países de origem anglo-saxã, como Inglaterra e Estados Unidos. Ao contrário do Civil Law, nesta tradição as fontes primárias do direito são os costumes, jurisprudência e precedentes, ou seja, o direito resulta de um "conjunto de interpretações das normas do direito proferidas pelo Poder Judiciário" (CARON, 2014, p. 68). Deve-se ressaltar que nos países em que é adotado tal sistema, há a previsão normativa, todavia, as leis, em conjunto com a jurisprudência e os precedentes, possuem grande importância nas resoluções de litígios. Neste contexto, Reale (2002, p. 110) expressa que o sistema Common Law consiste em um "Direito misto, costumeiro e jurisprudencial [...] coordenado e consolidado em precedentes judiciais, isto é, segundo uma série de decisões baseadas em usos e costumes prévios”.

Em decorrência do direito anglo-saxão ser pautado em sua jurisprudência e em costumes, o entendimento aplicado para solucionar um determinado caso, poderá servir de paradigma para situações idênticas ou semelhantes que se apresentem, vinculando as decisões dos magistrados. Tais fatos apresentam elementos originários e funcionais do sistema Common Law, neste seguimento, Caron (2014, p. 69) aduz:

No princípio, o Common Law, era um direito cuja fonte primária eram os costumes e a tradição, daí ter sido denominado de "direito comum", os quais eram então aplicados nos tribunais, transformando-se, então, em precedentes. Com o tempo, tais precedentes foram se transformando em jurisprudência, fortalecendo-se desse modo e impulsionando o sistema jurídico.

Com o advento do Novo Código de Processo Civil, o direito brasileiro recebeu uma grande mudança em seu sistema jurídico, auferindo influências tanto do Common Law quanto do Civil Law. No entanto, no instituto dos precedentes, é perceptível a maior tendência do direito processual brasileiro em assemelhar-se ao direito anglosaxão, nesta lógica, Theodoro Jr. (2015, p. 32) afirma que: 
O Novo Código de Processo Civil vai muito além e encaminha-se para uma aproximação maior com a common law, estendendo o dever de submissão ao precedente, principalmente àquele dos tribunais superiores, como regra geral, sem limitar-se às súmulas qualificadas como vinculantes (art. 926).

Isto posto, compreendido as tradições judiciárias e as fontes ensejadoras da teoria dos precedentes, passa-se a analisar do que se trata este novo instituto jurídico no direito brasileiro, seus objetivos para com o ordenamento pátrio, além de seus meios de formação.

\section{DOS PRECEDENTES JUDICIAIS E SUA FORMAÇÃO}

\subsection{DA RATIO DECIDENDI}

Antes de adentrar em outros pontos do debate acerca dos precedentes, se deve compreender no que consiste tal instituto. Para tanto, Braga, Didier Jr. e Oliveira (2015, p. 441) conceituam precedente como "a decisão judicial tomada à luz de um caso concreto, cujo elemento normativo pode servir como diretriz para o julgamento posterior de casos análogos". De igual modo, Donizetti (2016, p. 1270) afirma que os precedentes são "entendimentos firmados pelos tribunais que poderão servir de diretriz para o julgamento de casos semelhantes". Assim, abstraindo desses conceitos, se entende por precedentes o raciocínio aplicado às sentenças prolatadas acerca de um caso que se apresenta ao magistrado, em que serão utilizados em situações semelhantes ou idênticas que sujam posteriormente.

No que tange a obrigatoriedade de aplicação do precedente, é preciso esclarecer que o que vincula as decisões posteriores não é aquela decisão sedimentada, mas sim o raciocínio empenhado naquela sentença, a tese jurídica. Braga, Didier Jr. e Oliveira (2015, p. 442), neste sentido aduzem que apesar de "comumente se faça referência à eficácia obrigatória ou persuasiva do precedente, deve-se entender que o que pode ter caráter obrigatório ou persuasivo é a sua ratio decidendi". Assim, para os autores supracitados (2015) o precedente é o mesmo que a ratio decidendi. 
Nesta senda, a tese jurídica aplicada na fundamentação da decisão do juiz, também denominada pelo direito americano como holding, segundo Arenhart, Marinoni e Mitidiero (2015, p 873), consiste na razão de decidir, em:

Uma generalização das razões adotadas.como passos necessários e suficientes para decidir um caso ou as questões de um caso pelo juiz. Em uma linguagem própria à tradição romano-canônica, poderíamos dizer que a ratio decidendi deve ser formulada por abstrações realizadas a partir da justificação da decisão judicial.

Deste modo, entende-se por holding o raciocínio jurídico aplicado pelo magistrado sobre um caso sub judice para solucioná-lo, que poderá ser utilizado como paradigma em situações semelhantes ou idênticas que se apresentem ao judiciário. Durante a sentença, segundo Braga, Didier Jr. e Oliveira (2015), o juiz produz duas normas jurídicas, uma com um caráter geral, em que o magistrado adéqua os elementos constitutivos do caso concreto ao elemento normativo através de sua interpretação, esta norma, conforme os mesmo autores afirmam (2015, p. 447) advém da:

solução de um caso concreto (particular) extrai-se uma regra de direito que pode ser generalizada. Só se pode considerar como ratio decidendi a opção hermenêutica que, a despeito de ser feita para um caso concreto, tenha aptidão para ser universalizada.

A segunda norma jurídica que o juiz cria no momento de prolatar seu veredito possui uma concepção mais específica, haja vista que esta consiste no parecer para aquele quadro fático específico, que virá expresso no dispositivo da sentença. Somado a todos estes componentes da decisão, pode-se observar, segundo Braga, Didier Jr. e Oliveira (2015, p. 444) que "A decisão judicial é o ato jurídico de onde se extrai a solução do caso concreto, encontrável no dispositivo, e o precedente, comumente retirado da fundamentação". Deste modo, se o precedente comumente é retirado da fundamentação da decisão, além de ser o mesmo que a ratio decidendi, logo, é possível inferir que o holding é um componente de fundamentação da sentença judicial, tendo em vista que o mesmo se trata de uma tese jurídica aplicado à situações sob julgamento. 


\subsection{DO OBTER DICTUM}

Vele mencionar acerca do obter dictum, que traduzido literalmente significa dito de passagem, tendo em conta que este instituto jurídico se encontra presente na sentença, Arenhart, Marinoni e Mitidiero (2015, p 874) o conceituam como "aquilo que é dito durante um julgamento ou consta em uma decisão sem referência ao caso ou que concerne ao caso, mas não constitui proposição necessária para sua solução". Assim sendo, o dictum consiste nos elementos presentes na fundamentação da decisão, todavia, secundário a esta, podendo o assunto arguido ter conexão ou não com o conteúdo do parecer.

A importância deste instrumento está na possibilidade de servir de fundamento para uma futura superação de precedente, pois a presença de uma divergência de entendimento por parte de algum magistrado poderá servir como fundamento para dar prosseguimento ao julgamento de apelação devido a não unanimidade dos votos, conforme expressa o artigo 942 do Novo Código de Processo Civil (BRAGA; DIDIER JR.; OLIVEIRA, 2015). Desta forma, é clara a importância do obter dictum, tendo em vista que, mesmo não sendo um precedente, esta ligado a este, pois poderá suscitar sua superação, ou mesmo vindo a tornar-se um precedente no futuro, como expressa os autores supracitados (2015, p. 446) em:

O obiter dictum pode ser erigido à condição de ratio, bem como a ratio pode ser "rebaixada" à condição de obiter dictum.

De um lado, a identificação de obiter dictum no julgamento de casos prévios pode se tornar ratio no julgamento futuro de um hard case, contribuindo muito para sua solução - bem como de outros casos que a ele se assemelhem.

Portanto, este instituto possui extrema importância para casos concretos que sejam levados ao judiciário pela primeira vez, denominados no direito inglês como hard case, pois ainda não há a existência de precedentes à serem aplicados, assim, o obter dictum mencionado em um outro processo, poderá auxiliar o magistrado no momento de prolatar a sentença. 


\subsection{DO STARE DECISIS}

Uma doutrina de estrema importância aplicada ao direito brasileiro, oriunda do sistema Common Law, é o stare decisis, que consiste no respeito pelos tribunais inferiores aos entendimentos vinculantes sedimentados e uniformizados pelas Cortes recursais e supremas. Neste sentido, Arenhart, Marinoni e Mitidiero (2015, p 872) conceituam o stare decisis como:

A necessidade de compatibilização horizontal e vertical das decisões judiciais decorre da necessidade de segurança jurídica, de liberdade e de igualdade como princípios básicos de qualquer Estado Constitucional. Normalmente, a imprescindibilidade dessa compatibilização é retratada pela máxima stare decisis et quieta non movere, que determina o respeito aos precedentes das Cortes Supremas e à jurisprudência vinculante produzida pelas Cortes de Justiça.

O stare decisis pode ser aplicado de forma horizontal, que consiste no respeito dos tribunais aos próprios precedentes e jurisprudências. Enquanto que o stare decisis empregado de modo vertical corresponde no respeito, por parte dos órgãos jurisdicionais inferiores, às orientações e jurisprudências sedimentadas pelos tribunais superiores (ARENHART; MARINONI; MITIDIEIRO, 2015).

\subsection{DA APLICAÇÃO DOS PRECEDENTES E DO STARE DECISIS NO NOVO CÓDIGO DE PROCESSO CIVIL}

Como observado no tópico anterior, a doutrina do stare decisis é adotada de duas formas pelo direito processual civil, tem-se que a aplicação horizontal se encontra prevista no artigo 926 do códex de ritos (BRASIL, 2015), que expressa que "Os tribunais devem uniformizar sua jurisprudência e mantê-la estável, íntegra e coerente". Deste modo, os tribunais regionais e os superiores estão obrigados a sedimentarem suas decisões através das resoluções de incidentes de demandas repetitivas, do incidente de assunção de competência, Recursos Especiais e Recursos Extraordinários, além do dever de respeita-las, aplicando o mesmo raciocínio aos casos concretos semelhantes que se apresentem. Arenhart, Marinoni e Mitidiero (2015, p 872) 
firmam que "a necessidade de stare decisis horizontal decorre do princípio da segurança jurídica, notadamente da necessidade de estabilidade do sistema jurídico".

No que tange ao stare decisis vertical, entende-se como matérias a serem observadas previamente pelos juízes antes de prolatarem suas decisões, tendo em vista que 0 magistrado deverá respeitar e decidir conforme 0 entendimento sedimentado dos tribunais recursais e superiores. Ressalta-se que os precedentes a serem observados pelos juízes de primeiro grau são os provenientes dos incidentes e recursos acima mencionados. Tal preceito se encontra previsto no artigo 927 do Código de Processo Civil de 2015 (BRASIL, 2015), que aduz:

Os juízes e os tribunais observarão:

As decisões do Supremo Tribunal Federal em controle concentrado de constitucionalidade;

Os enunciados de súmula vinculante;

Os acórdãos em incidente de assunção de competência ou de resolução de demandas repetitivas e em julgamento de recursos extraordinário e especial repetitivos;

Os enunciados das súmulas do Supremo Tribunal Federal em matéria constitucional e do Superior Tribunal de Justiça em matéria infraconstitucional; A orientação do plenário ou do órgão especial aos quais estiverem vinculados.

A importância da aplicação destas doutrinas, principalmente a stare decisis e dos precedentes, se dá pela busca do direito brasileiro em alcançar o emprego efetivo do princípio da segurança jurídica, equidade e celeridade processual, considerando-se que o objetivo do cidadão ao entregar ao Estado o dever de dirimir os conflitos que surjam, ao invés de empregar a força física, é a confiança de que aquela decisão será a mesma aplicada em casos semelhantes, bem como esta decisão não se altere com facilidade, além da resolução da lide o mais breve possível. Todas estas finalidades e princípios são metas a serem alcançadas com o emprego da teoria dos precedentes. No entanto, existem críticas quanto a aplicação deste novo instituto pelo Novo Código de Processo Civil brasileiro, conforme apresentado no capítulo seguinte.

\section{DA CRÍTICA À TEORIA DOS PRECEDENTES}

O projeto do novo código de processo civil foi amplamente discutido por doutrinadores e estudiosos da área jurídica processual, com o intuito de criar um codéx 
de ritos inovador, que atenda as deficiências do direito brasileiro, abarcando todos os pontos críticos observados pela prática quotidiana. Neste sentido, um ponto de extrema importância é a segurança jurídica das decisões, objetivo pretendido pela teoria dos precedentes.

Contudo, durante a criação do projeto do novo código, no decurso da vacância e mesmo na vigência, uma crítica ferrenha paira sobre o sistema dos precedentes, tratase do engessamento do direito, a possibilidade das decisões acerca de um determinado caso concreto, uniformizadas pelos tribunais de segunda instância ou superiores, que servirão de parâmetros para outras situações, serem tão previsíveis e imutáveis, ocasionando a não apreciação de novas demandas, desestimulando o cidadão à acionar o poder judiciário pleiteando por seu direito, mesmo sendo contrário a uma decisão sedimentada, haja vista conhecer o resultado antecipadamente, impedindo que novos debates surjam acerca daquele tema. Tal afirmativa se dá pela interpretação dada aos artigos 926, 927, 932, 332, entre outros, do Código de Processo Civil (CPC) de 2015, tendo em conta que o artigo 926, trata do "dever genérico de os tribunais brasileiros uniformizarem sua jurisprudência, mantendo-a estável, íntegra e coerente" (BRAGA; DIDIE JR.; OLIVEIRA, 2015, p. 461). Deste modo, os tribunais deverão sedimentar suas decisões por meio de súmulas, que servirão de parâmetro para os juízes ou tribunais inferiores, quando prolatar da sentença, conforme expõe o artigo 927 CPC.

Baseando-se no artigo 927 do CPC, pode-se verificar que os precedentes podem ter efeitos jurídicos diversos, sendo eles “(i) vinculante/obrigatório (art. 927, CPC); (ii) persuasivo; (iii) obstativo da revisão de decisões; (iv) autorizante; (v) rescindente/deseficacizante; e (vi) de revisão da sentença." (BRAGA, DIDIE JR, OLIVEIRA, 2015, p. 454). Todas estas gradações de cada tipo de precedentes devem ser seguidas, algumas mais impositivas que outras, como o caso das de caráter vinculante, súmula vinculante e decisões do Supremo Tribunal Federal em controle concentrado de constitucionalidade.

Em outras situações, notadamente nos institutos previstos no inciso terceiro do artigo 927 do Código de Processo Civil (BRASIL, 2015), que aduz "os acórdãos em incidente de assunção de competência ou de resolução de demandas repetitivas e em 
julgamento de recursos extraordinário e especial repetitivos", a não observação de tais precedentes pelos magistrados ao julgarem uma determinada demanda, poderá resultar em reclamação da parte interessada com o fito de preservar a proteção e garantir a observância da competência, da autoridade do tribunal prolator, de súmula vinculante, ou qualquer outro precedente desrespeitado, como preconiza o artigo 988 do códex de ritos (BRASIL, 2015).

No precedente obstativo da revisão de decisões, caberá ao juiz aplicar o entendimento sedimentado por tribunais superiores acerca do assunto discutido, prolatando sua sentença, ou impedindo que o recurso seja recebido pelo tribunal recursal para que haja uma rediscussão da demanda, neste sentido, Braga, Didier Jr., Oliveira (2015, p. 457) esclarece:

O efeito obstativo (assim como os outros tipos eficaciais que se seguem) não deixa de ser, em última análise, um desdobramento do efeito vinculante de certos precedentes. Em algumas situações, o legislador permite que o órgão jurisdicional negue provimento (ou seguimento) a determinados recursos ou dispense a remessa necessária quando estiverem eles em conflito com precedentes judiciais - jurisprudência ou súmula que a partir deles se constitua , sobretudo com aqueles emanados das cortes superiores.

O artigo 932, inciso IV do Código de Processo Civil (BRASIL, 2015) trás expresso que o relator do processo poderá negar provimento à recurso que contrariar precedentes vinculantes. De igual modo o artigo 332 da nova Lei processual (BRASIL, 2015), que trata do julgamento improcedente no limiar do processo, quando o juiz verificar que a matéria arguida também contrariar precedentes vinculativos, nas causas que dispensem a fase instrutória, independentemente da citação do réu. Percebe-se que o intuito do legislador ao determinar estes procedimentos é fazer com que ocorra certa aceleração do julgamento por decisões monocráticas e liminares, que haja a análise do mérito, a sentença e crie coisa julgada, além de que diminua a quantidade de demandas idênticas, bem como, atenue o número de recursos, alcançando o princípio da celeridade processual, segurança jurídica, assim como minimize a onerosidade do judiciário devido o grande volume de processos. Neste sentido, Gonçalves (2016, p. 431), tratando dos benefícios e objetivos pretendidos pelo texto do artigo 332 do CPC, leciona que: 
A aplicação do dispositivo atribui ao juiz a possibilidade de julgar mais rapidamente processos que versam sobre determinada questão jurídica que, por sua repetição e multiplicidade, deram ensejo à edição de súmula ou ao julgamento repetitivo. São conhecidas as situações em que determinadas teses jurídicas dão ensejo a uma multiplicação de processos, nos quais se discute a mesma questão de direito. Para acelerar-lhes o julgamento é que o novo dispositivo foi introduzido.

A crítica ao sistema dos precedentes reside nos argumentos acima apresentados, no raciocínio de que o direito estaria paralisado, imutável, em virtude, por exemplo, do julgamento liminar da demanda contrária a súmulas, ou ao óbice de recursos quando sua matéria for diversa ao entendimento dos tribunais superiores. Nesta perspectiva, o magistrado haveria perdido a possibilidade de livre convencimento de decidir devido à nova sistemática trazida pelo código de 2015, bem como, o advento da teoria dos precedentes enclausurou a oportunidade de mudança dos conteúdos das decisões e interpretações dos fatos apresentados por parte dos juízes, ocasionando um efeito nocivo ao jurisdicionado.

Este debate sobre a possível inductilidade das decisões foi ventilada, porém com pouca influência, haja vista que a concepção majoritário dos doutrinadores processualistas civilistas quanto a aplicação dos precedentes, consiste na garantia da segurança jurídica e equidade nas sentenças, proporcionando institutos jurídicos que assegurem a superação destes em caso de inaplicabilidade proveniente de uma evolução social e de entendimento.

\section{A ADEQUAÇÃo dos PRECEDENTES À MUTABILIDAdE dO DIREITO: MECANISMOS DE SUPERAÇÃO DOS PRECEDENTES}

Aqueles que defendem que os precedentes ocasionariam um engessamento do direito, observam a aplicação da teoria no novo código de processo civil apenas por um ângulo, não se atendo aos mecanismos previstos para garantirem a evolução do pensamento jurídico e social que de tempos em tempos se modificam, cabendo ao direito acompanhar e se adequar.

A finalidade do sistema de precedentes é garantir a segurança jurídica, a aplicação igualitária do direito independente das partes, quando os casos concretos posteriores forem idênticos, estabelecendo certa rigidez na opinião consolidada pelos 
tribunais superiores, todavia, sem que sejam descartadas futuras mudanças. Para que tais transformações ocorram, deverá haver profundas discussões sobre os fundamentos que podem motivar a superação do entendimento anterior, haja vista que a fragilidade das decisões judiciais avilta o princípio da segurança jurídica, que por sua vez é objetivo dos precedentes. Neste sentido, Marinoni (2010, p. 27) explica:

Para que o cidadão possa esperar um comportamento ou se postar de
determinado modo, é necessário que haja univocidade na qualificação das
situações jurídicas. Além disso, há que se garantir-lhe previsibilidade em
relação às consequências das suas ações. O cidadão deve saber, na medida
do possível, não apenas os efeitos que as suas ações poderão produzir, mas
também como os terceiros poderão reagir diante delas. Note-se, contudo, que a
previsibilidade das consequências oriundas da prática de conduta ou ato
pressupõe univocidade em relação à qualificação das situações jurídicas, o que
torna esses elementos indissociavelmente ligados.

Este rigor observado na aplicação dos precedentes sobre as decisões dos tribunais inferiores, não é comumente observado em países com o sistema jurídico semelhante ao brasileiro, Civil Law nestes países os magistrados das cortes inferiores não são obrigados a acompanhar os precedentes definidos pelos tribunais recursais, e o descumprimento não se configura como desobediência, mas sim como garantia de independência do juiz (PEIXOTO, 2015). Todavia, no Código de Processo Civil de 2015, a forma de lidar com os precedentes é diversa, conforme explanações anteriores, o objetivo desse instituto suscitado pelo novo códex de ritos é criar padrões de decisões a serem aplicadas em casos análogos, ao mesmo tempo em que proporciona artifícios de superação (overruling) e distinção (distinguishing) dos precedentes, meios de garantir a evolução do direito.

$\mathrm{Na}$ eventualidade de um precedente se encontrar defasado, fora dos padrões de aceitação social, em que sua aplicação não irá condizer com o momento, então o precedente deve ser superado, devendo ser apresentado outro entendimento por parte do tribunal superior que o criou. Segundo Braga, Didier Jr. e Oliveira (2015, p. 494), overruling consiste em uma "técnica através da qual um precedente perde a sua força vinculante e é substituído (overruled) por outro precedente. O próprio tribunal, que firmou o precedente pode abandoná-lo em julgamento futuro, caracterizando o overruling". Quanto as motivações para a superação da decisão estabelecida, Arenhart, Marinoni e Mitidiero (2015, p 875) explanam: 
A superação de um precedente (overruling) constitui a resposta judicial ao desgaste da sua congruência social e coerência sistêmica. Quando o precedente carece desses atributos, os princípios básicos que sustentam a regra do stare decisis- segurança jurídica e igualdade - deixam de autorizar a sua replicabilidade (replicability), com o que o precedente deve ser superado. Essa conjugação constitui a norma básica que rege a possibilidade de superação de precedentes.

No momento em que o tribunal percebe a necessidade da superação do precedente, esta é sinalizada (signaling), vindo a suceder o overruling em algum julgamento posterior. Esta determinação está prevista na doutrina jurídica brasileira, bem como no artigo 927, $§ 3^{0}$ do Novo Código de Processo Civil (BRASIL, 2015), o qual afirma que:

$\mathrm{Na}$ hipótese de alteração de jurisprudência dominante do Supremo Tribunal Federal e dos tribunais superiores ou daquela oriunda de julgamento de casos repetitivos, pode haver modulação dos efeitos da alteração no interesse social e no da segurança jurídica.

O overruling pode se dividir em duas categorias, a superação expressa (express overruling), que ocorre quando o tribunal determina claramente a aplicação de um novo entendimento para o caso concreto que se apresente, e a todos os posteriores idênticos, abandonando o raciocínio anterior (BRAGA; DIDIER JR.; OLIVEIRA, 2015). A superação tácita ou implícita (implied overruling) acontece quando a corte que criou 0 precedente aplica uma nova concepção que é contrária ao predecessor, todavia, sem se manifestar claramente sobre a superação (BRAGA; DIDIER JR.; OLIVEIRA, 2015). Dentro do implied overruling há um subitem, a transformation ou transformação, que segundo Braga, Didier Jr. e Oliveira (2015, p. 495), consiste em:

Há também quem faça menção à transformation, que seria uma técnica pela qual o tribunal, embora deixe de aplicar o precedente, tenta compatibilizar as duas orientações. Trata-se de um implied overrulin ao quadrado, no sentido de que, além de revogar a orientação anterior de forma implícita, ainda tenta compatibilizá-la com o novo precedente.

Na transformação (trasformation) dos precedentes, os magistrados realizam uma "reciclagem" do entendimento sedimento, tendo em vista que há uma superção de maneira implícita, ou seja, a nova orientação se sobrepõe a antecedente sem que haja uma fundamentação clara, expressa, tentando aplicar a decisão anterior no novo raciocínio. O segundo tipo de overruling, bem como o seu subitem, não são admitidos 
pelo ordenamento jurídico brasileiro, pois contrariam a previsão do artigo $927, \S^{\circ}$ do CPC, que determina a devida e específica fundamentação para modificar enunciado de súmula, jurisprudência pacificada ou de tese adotada em julgamento de casos repetitivos (BRASIL, 2015). Outra previsão acerca da superação de precedentes se encontra no $\S 2^{\circ}$ do artigo 927 do Novo Código de Processo Civil, este dispositivo estabelece a possibilidade da superação ser precedida por um debate em audiências públicas, com a participação de entidades ou pessoas que possam contribuir para o melhor entendimento e discussão (BRASIL, 2015).

Ainda tratando do overruling, a doutrina e a lei trazem a possibilidade da superação ocorrer de formas diferentes, os meios de incidência previstos pelo direito brasileiro são o overruling difuso e overruling concentrado. O primeiro ocorre quando há um precedente a ser aplicado a uma lide que se apresenta à corte, porém existe a possibilidade deste precedente ser superado. Nesta situação, o tribunal poderá utilizar do parecer de pessoas ou entidades que tenham conhecimento da causa para fundamentar a suplantação. O overruling difuso é o padrão utilizado no sistema Common Law. O segundo meio de aplicar a superação de um precedente, sendo este método admitido pelo direito brasileiro, opera-se por um procedimento autônomo próprio, em que o tribunal analisa a orientação sedimentada com o intuito de modifica-la (BRAGA; DIDIER JR.; OLIVEIRA, 2015). O pedido de apreciação da tese firmada com intuito de superá-la, por intermédio de um procedimento, encontra-se previsto no artigo 986 do Código de Processo Civil de 2015, que aduz "a revisão da tese jurídica firmada no incidente far-se-á pelo mesmo tribunal, de ofício ou mediante requerimento dos legitimados mencionados no art. 977, inciso III" (BRASIL, 2015). Ressaltando que os legitimados mencionados pelo artigo 986, remetido ao 977, inciso III do CPC, tratam-se do Ministério Público ou Defensoria Pública.

Outro meio de aplicação do overruling se dá com a utilização, de forma antecipada por um juiz ou tribunal inferior que não estabeleceu o precedente, ao deixar aplica-lo por entender que a decisão do tribunal superior acerca da orientação sedimentada não condiz com a concepção social daquele momento, ou qualquer outra alteração no parecer que possa ter sido sinalizado pela corte, tal mecanismo é 
denominado de antecipatory overruling, conceituado por Braga, Didier Jr. e Oliveira (2015, p. 506) como uma:

Espécie de não-aplicação preventiva, por órgãos inferiores, do precedente firmado por Corte superior, nos casos em que esta última, embora sem dizê-lo expressamente, indica uma alteração no seu posicionamento quanto a precedente outrora firmado [...] É importante perceber que a fundamentação dessa técnica não está relacionada com uma anterior revogação do precedente pela Corte superior, mas sim, no sentido de que ele ainda é supostamente válido, mas que, por diversos motivos, tende a ser modificado, conforme por ela sinalizado, não mais devendo ser aplicado por não estar em consonância com a atual tendência do tribunal superior.

Ressalta-se que a não aplicação do precedente por parte do magistrado, ou tribunal inferior, não consiste em uma fundamentação pautada na discordância de entendimento do mérito, mas o objetivo é a evolução do direito e a flexibilidade do stare decisis, haja vista que a revogação de um precedente é por demais dificultosa (BRAGA; DIDIER JR.; OLIVEIRA, 2015). Complementando o raciocínio acerca da superação antecipada e seus legitimados para sua aplicação, correspondendo, como mencionado, a qualquer juiz ou tribunal inferior, que não estabeleceu o precedente, Ataíde Jr. e Peixoto (2014, p. 279) afirmam que:

Defende-se, neste trabalho a possibilidade de aplicação do anticipatory overruling no direito brasileiro. Presentes aqueles fundamentos que justificam a utilização do instituto, os tribunais estaduais ou os tribunais regionais federais, e, mesmo os juízes de primeira instância estariam autorizados a não aplicar os precedentes vinculantes dos tribunais superiores aos casos em julgamento.

Outra técnica de superação de precedentes é o overriding, que consiste em uma restrição de aplicação do entender de um precedente devido o surgimento de uma norma que contraria o raciocínio prévio. Esta delimitação da percepção abstraída do overriding não revoga o primeiro precedente, segundo Donizetti (2016, p. 1290), o overriding ocorre quando o "tribunal apenas desejar limitar o âmbito de incidência de um precedente em razão da superveniência de outra regra ou princípio legal. Aqui não há revogação por completo ou substituição por outro precedente". Destaca-se que o referido instrumento de superação não aborda o contexto fático da questão analisada pela corte, mas sim o quadro jurídico que foi alterado por uma nova compreensão (BRAGA; DIDIER JR.; OLIVEIRA, 2015). 
Rebatendo as críticas à teoria dos precedentes, quanto as afirmações de que o magistrado teve tolhido o direito de livre convencimento, impedindo-o de expressar o seu parecer acerca do caso apresentado, há um mecanismo estabelecido pelo Novo Código de Processo Civil que se adequa a este contexto, trata-se da distinção, ou dintinguishing. Braga, Didier Jr. e Oliveira (2015) afirmam se tratar de uma técnica de confronto, interpretação e aplicação do precedente. Neste caso, os juízes se preocupam em analisar as condições que the apresentem para então poderem prolatar uma sentença. Estes devem observar o precedente que poderá ser aplicado no caso em questão, se os fatos a serem julgados realmente são idênticos ou apenas semelhantes, verificar as diferenças em relação à orientação pacificada. Todas estas questões devem ser exploradas, pois havendo discrepâncias fáticas entre as situações, em julgamento e paragonada, deverá o magistrado apresentar as divergências encontradas por meio da distinção, o confronto, deixando de aplicar o precedente ao caso concreto. Isto posto, Arenhart, Marinoni e Mitidiero (2015, p 874), acerca do distinguishing aduzem que:

Devidamente identificado o precedente, é preciso saber quando esse é aplicável para solução de uma questão e quando não o é. Se a questão que deve ser resolvida já conta com um precedente - se é a mesma questão ou se é semelhante, o precedente aplica-se ao caso. O raciocínio é eminentemente analógico. Todavia, se a questão não for idêntica ou não for semelhante, isto é, se existirem particularidades fático-jurídicas não presentes - e por isso não consideradas - no precedente, então é caso de distinguir o caso do precedente, recusando-Ihe aplicação. É o caso de realizar uma distinção (distinguishing).

Tendo o juiz detectado a distinção entre o quadro sub judice e os fatos geradores do precedente, este poderá tomar duas medidas para solucionar a questão. A primeira consiste em dar aos argumentos que constituem a situação uma interpretação restritiva (restrictive distinguishing), baseando-se nos fatos que são diferentes, impedindo a aplicação do precedente, devendo, portanto, fundamentar sua sentença livremente, não estando adstrito à nenhum entendimento anterior (BRAGA; DIDIER JR.; OLIVEIRA, 2015), tal prática encontra-se prevista no artigo 489, $\S 1^{\circ}$, $\mathrm{VI}$, e outros, do CPC (BRASIL, 2015), que expressa:

Não se considera fundamentada qualquer decisão judicial, seja ela interlocutória, sentença ou acórdão, que: [...]deixar de seguir enunciado de súmula, jurisprudência ou precedente invocado pela parte, sem demonstrar a 
existência de distinção no caso em julgamento ou a superação do entendimento.

A segunda conduta que pode ser praticada pelo juiz após a distinção é realizar uma interpretação extensiva (ampliative distinguishing), entendendo que mesmo havendo divergência na materialidade do caso em questão e os fatos ensejadores do precedente aplicável, aplicar-se-á a mesma solução conferida aos casos anteriores. A fundamentação jurídica para tal conduta encontra figura normatizada no artigo 489, $\S$ 1ํ, V do códex de ritos de 2015, que aduz:

Não se considera fundamentada qualquer decisão judicial, seja ela interlocutória, sentença ou acórdão, que: [...] se limitar a invocar precedente ou enunciado de súmula, sem identificar seus fundamentos determinantes nem demonstrar que o caso sob julgamento se ajusta àqueles fundamentos.

Desta forma, todas estas técnicas de superação das orientações dos tribunais superiores demonstram que a teoria dos precedentes permite a mobilidade do direito, tendo em vista que este deve estar sempre atinente aos padrões e evoluções da sociedade, neste sentido Braga, Didier Jr. e Oliveira $(2015,495)$ afirmam que:

A possibilidade de mudança do entendimento é inerente ao sistema de precedentes judiciais. $O$ dever de estabilidade da jurisprudência não impede a alteração do entendimento, ele impede alteração injustificada desse entendimento. A modificação do entendimento pode revelar-se um imperativo de justiça. Este é o ponto.

Portando, constata-se tanto pelo novo ordenamento processual civil, bem como pela doutrina majoritária, que a teoria dos precedentes, aplicada ao direito brasileiro, apesar de objetivar a segurança jurídica e equidade através de uma maior previsibilidade das decisões judiciais, não resultará em um engessamento destas, haja vista a presença da mecanismos tipificados no Código de Processo Civil de 2015, e sua miríade de aplicações, que visam coibir a possibilidade de imutabilidade das sentenças e seus raciocínios sedimentados.

\section{CONCLUSÃO}

Isto posto, observa-se que o Novo Código de Processo Civil, juntamente com os institutos jurídicos que o acompanham, possuem o objetivo de solucionar problemas 
que o direito brasileiro sofria a anos, como a falta de segurança jurídica e equidade nas decisões judiciais, tendo em vista que as sentenças eram divergentes, variavam entre os magistrados, mesmo que os casos sub judice fossem idênticos, ou semelhantes. Em vista de tais questões, a teoria dos precedentes em conjunto com a doutrina do stare decisis buscam trazer soluções, uma vez que agem diretamente nestes impasses.

As críticas à teoria dos precedentes, no que tange a possibilidade das decisões do judiciário virem a se tornar imutáveis e engessassem o direito, não possuem fundamento, tendo em conta que a teoria dos precedentes, ao passo que trás certa rigidez às decisões judiciais buscando a segurança jurídica e equidade, também apresenta mecanismos de superação dos mesmos precedentes, pois os magistrados precisam estar atentos a mudanças sociais que ocorrem, devendo o direito se adequar aos padrões para que possa representar os anseios da população e a sua devida regulação.

\section{REFERÊNCIAS}

ARENHART, Sérgio Cruz; MARINONI, Luiz Guilherme; MITIDIERO, Daniel. Novo Código de Processo Civil Comentado. São Paulo: Saraiva, 2015.

ATAÍDE JR., Jaldemiro Rodrigues de; PEIXOTO, Ravi. Flexibilidade, strare decisis e o desenvolvimento do anticipatory overruling no direito brasileiro. Revista de Processo. Vol. 236, 2014.

BRAGA, Paulo Sarno; DIDIER JR., Fredie; OLIVEIRA, Rafael Alexandria. Curso de Direito Processual Civil: teoria da prova, direito probatório, ações probatórias, decisão, precedente, coisa julgada e antecipação dos efeitos da tutela. 10 ed., Salvador: Jus Podivm, 2015. v. 2

BRASIL. Lei no 13.105, de 16 de março de 2015. Disponível em: < http://www.planalto.gov.br/ccivil_03/_ato2015-2018/2015/lei//13105.htm> Acesso em: 10 fev. 2017.

CARON, Déborah. Teoria dos precedentes judiciais e sua eficácia para garantia da segurança jurídica. Revista da Faculdade de Direito - UFU, v. 42, n. 1, p. 66-85, 2014.

DONIZETTI, Elpídio. Curso Didático de Direito Processual Civil. 19. ed. São Paulo: Atlas, 2016. 
GONÇALVES, Marcos Vinícius Rios. Direito processual Civil Esquematizado. 6. ed. São Paulo: Saraiva, 2016.

MARINONI, Luiz Guilherme. O precedente na dimensão da segurança jurídica. In: A força dos precedentes. Estudos dos cursos de mestrado e doutorado em direito processual civil da UFPR. 2. ed. Salvador: Juspodivm, 2012.

NADER, Paulo. Introdução ao estudo do direito. 33. ed. Rio de Janeiro: Forense, 2011.

PEIXOTO, Ravi. Superação do Precedente e Segurança Jurídica. Salvador: Juspodvm, 2015.

REALE, Miguel. Lições preliminares de direito. 27 ed. São Paulo: Saraiva, 2002.

THEODORO JR, Humberto. Curso de Direito Processual Civil. 56. ed. Rio de Janeiro: Forense, 2015. v. 1. 